\title{
Fuzzy Multicriteria Risk Assessment for Hazardous Waste Management: The Case Of Istanbul
}

\author{
Seda Uğurlu \\ Istanbul Technical University, Industrial Engineering Department, 34367 Macka, Istanbul Turkey \\ sedayanik@itu.edu.tr \\ Cengiz Kahraman* \\ Istanbul Technical University, Industrial Engineering Department, 34367 Macka, Istanbul Turkey \\ kahramanc@itu.edu.tr
}

\begin{abstract}
A hazardous waste is waste that poses substantial or potential threats to public health or the environment. Hazardous waste management is an area of the waste management field concerned with the proper containment, management, and disposal of wastes which could be considered hazardous. In this paper, we use a multicriteria evaluation method, namely VIKOR, for various hazardous waste treatment alternatives under fuzzy environment. These alternatives are physical treatment processes, chemical treatment processes, thermal treatment processes, and biological treatment processes. Under the main criteria, economic, risks, and technical, we consider 11 sub-criteria. The fuzzy set theory let us use linguistic evaluations for the alternatives.
\end{abstract}

Keywords: fuzzy sets, VIKOR, multicriteria evaluation, waste management, hazardous waste, risk assessment

${ }^{*}$ Corresponding author. 


\section{Introduction}

Hazardous waste has a chemical composition or other properties that have to be managed in order to prevent its release into the environment that can result in illness, death or other harm to living organisms including humans. The word "waste" means that the substances of concern have no apparent value. And a "hazard" is expressed as the potential of an unacceptable outcome ${ }^{1}$. The identification of a waste as hazardous waste is the process to determine whether a waste poses a sufficient chemical or physical hazard to merit regulation. At first glance, one would imagine that distinguishing between hazardous and nonhazardous wastes is a simple matter of chemical and toxicological analysis. Other factors must be considered, however, before evaluating the actual hazard posed by a waste's chemical composition $^{2}$. The hazardous waste has one or more hazard characteristics given in Table 1. alternative technologies are seek to destroy, stabilize, or treat hazardous wastes by changing their chemical, biological or physical characteristics. The environmental and public health concerns increasingly stringent regulatory climate and encourage the hazardous waste management as a cleanup business ${ }^{3}$.

A hazardous waste management scheme must be justified in terms of scientific evidence, engineering designs and processes, technologic practicality, economic realities, ethical considerations, and local, state, and national regulations ${ }^{1}$. The regulations generally provide a control on the risks associated with hazardous waste which is defined as the likelihood that harm will occur when a receptor (e.g., human or a part of an ecosystem) is exposed to that hazard. Hazardous waste risk range from toxic risks which the probability that a certain population will have an incidence of a particular illness to other risks such as ecosystem stress, loss of important habitats, decreases in the size of the

Table 1. Four Types of Characteristics of Hazardous Wastes.

\begin{tabular}{lll}
\hline Hazard & Criteria & Physical/Chemical Classes \\
\hline Corrosivity & $\begin{array}{l}\text { Able to destroy tissue by chemical } \\
\text { reactions. }\end{array}$ & $\begin{array}{l}\text { Acids, bases, and salts of strong acids and strong bases. They } \\
\text { have a pH less than } 2.0 \text { or higher than 12.5. (e.g. rust removers, } \\
\text { waste acid, alkaline cleaning fluids, and waste battery fluids) }\end{array}$ \\
Ignitability & Able to oxidize by burning. & $\begin{array}{l}\text { Any substance that spontaneously combusts at } 54.3^{\circ} \mathrm{C} \text { in air or } \\
\text { at any temperature in water, or any strong oxidizer. (e.g. paint } \\
\text { and coating wastes, some degreasers, and other solvents) }\end{array}$ \\
Reactivity & $\begin{array}{l}\text { Able to react, detonate, or decompose } \\
\text { explosively at environmental } \\
\text { temperatures and pressures. }\end{array}$ & $\begin{array}{l}\text { A reaction usually requires a strong initiator such as an } \\
\text { explosive, confined heat or explosive reactions with water. } \\
\text { (e.g. wastes from cyanide-based plating operations, bleaches, } \\
\text { waste oxidizers, and waste explosives) }\end{array}$ \\
& $\begin{array}{l}\text { Causing harm to organisms soon after } \\
\text { Toxicity }\end{array}$ & $\begin{array}{l}\text { Toxic chemicals include pesticides, heavy metals, and mobile } \\
\text { or volatile compounds that migrate readily. }\end{array}$ \\
\hline
\end{tabular}

The "hazard" or toxicity (hazards to human health) of the waste is the most important factor in determining how a waste should be managed. Hazardous waste is required to undergo a proper treatment to destroy or render them environmentally acceptable. Handling and disposal of hazardous waste and attending requirements have been substantially expanded and subject not only to technology needs but to the hazardous waste regulatory environment. Hazardous waste management alternatives such as landfilling of wastes are discouraged with the recent regulations whereas new population of sensitive species, public safety and public welfare hazards. The wide range of risks encountered requires specific solutions often at high costs. Facilities that generate, transport, transfer, treat or dispose of hazardous wastes require substantial construction, operating costs and have become extremely expensive and complex. There are usually a range of treatment alternatives for various types of hazardous wastes and their components dependent upon physical and/or chemical properties ${ }^{3}$. A challenge of hazardous waste management is the selection of treatment alternative 
considering the technical, economical and risk associated aspects. The aspects of the problem are usually represented in the form of multiple criteria which often express tradeoffs between the management objectives. In order to raise awareness of the tradeoffs between the objectives and compare the differences among the alternatives in an optimizing framework, hazardous waste management decision making may depend upon multiple criteria decision making (MCDM) models which promote participation and synthesis of a wide variety of information.

Hazardous waste management is a complex issue not only because of its broad scope but also because of the wide range of attributes to be assessed. Specifically, risk assessment in hazardous waste management and the comparison of the estimated relative risks or impacts associated with each management alternative relies on attributes and parameters difficult to define with certainty. The components of the risk assessment and decision making process involve both quantitative and qualitative factors. These difficulties constitute a method such as fuzzy logic to be used for integrating the risk levels, uncertainty and valuation mathematically in decision making of hazardous waste management.

In this paper, we aim to present a fuzzy VIKOR methodology to make a multicriteria selection among the treatment alternatives of hazardous waste management. The proposed methodology is applied to a problem case of Istanbul to demonstrate the potential of the methodology.

The rest of this paper is organized as follows. The regulations of hazardous waste management are reviewed in Section 2. A summary of the literature on multicriteria decision making for hazardous waste management is given in Section 3. Section 4 includes a brief description of the treatment methods used in hazardous waste management. Then the criteria for the selection of the treatment method are explained in Section 5. The fuzzy VIKOR multicriteria decision making methodology is introduced in Section 6. An application is presented in Section 7. The obtained results and future research directions are discussed in Section 8.

\section{Hazardous Waste Management}

The waste amount has increased dramatically after the industrial revolution with the growing consumption of goods. Chemical accidents, spills of hazardous waste or illegal midnight dumping that contaminates property are familiar. Yet, even when hazardous waste is managed or disposed of in a careful manner, it may still pose a serious threat to public health and the environment. For example, toxic hazardous wastes can leak from a poorly constructed or improperly maintained hazardous waste landfill. Such waste contamination can pollute groundwater, the primary source of drinking water for half the nation ${ }^{2}$.

In order to prevent from these severe and irreversible results of the mismanagement of hazardous waste, nations have developed comprehensive regulations and standards. The recognition of the need for regulations is not very old and the first release of the acts of hazardous waste management differs among nations. The first national directives were enacted in 1972 at Germany, in 1976 at USA and in 1995 at Turkey. The common aim of these acts is to create a framework for the management of hazardous waste safely from the moment it is generated; while it is transported, treated, or stored; until the moment it is disposed. The management systems of hazardous waste regulated by the acts mainly establish requirements for the following ${ }^{2}$ :

- Procedures for hazardous waste identification and classification.

- Provisions for facilitating hazardous waste recycling and universal wastes safely

- Standards for hazardous waste generating facilities

- Regulations for waste reduction and minimization

- Regulations for hazardous waste transporters

- Standards and provisions for treatment, storage, and disposal facilities and units

- Restrictions on land disposal

- Standards on units conducting combustion of hazardous waste.

- Designing corrective action against any spills or releases into the environment

- Permitting, inspection and enforcement based on these regulations

As listed above, hazardous waste management comprises a diverse range of activities including identification, reduction, recycling, segregation, modification, treatment and disposal. These activities can be classified in two folds. One fold is the activities aiming to produce less amount of waste such as 
reduction and recycling. Yet, an amount of waste is generated that need to be dealt with the second fold of the activities, namely treatment or disposal. A general overview of the hazardous waste management is illustrated in Figure 1.

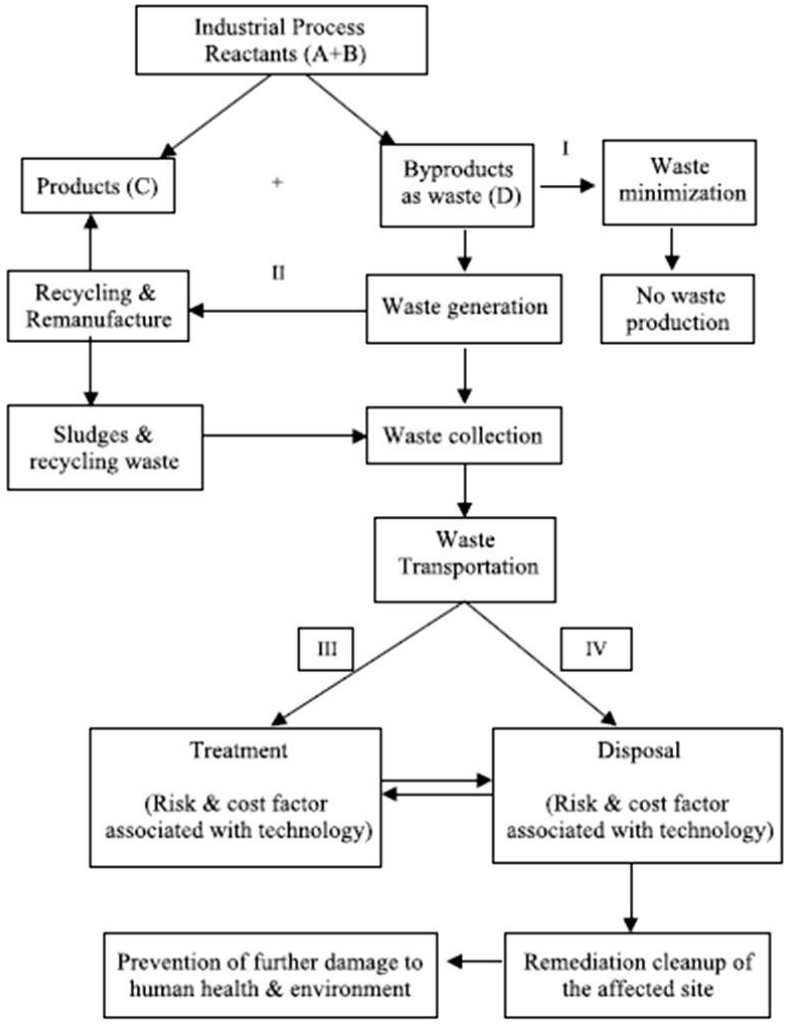

Fig.1. Hazardous waste management ${ }^{4}$.

Historically, disposal was presented as a form of treatment on the grounds that after disposal the characteristics of deposited wastes frequently changed as a result of degradation, a phenomenon that greatly increases the potential of hazards on human health and environmental pollution. Thus, disposal methods such as land filling, dumping or spilling have been restricted with additional precautions designed to protect soil, water, and air resources. Treatment of the hazardous waste is the ultimate aim to remove or modify the characteristics of a substance that render it hazardous and perhaps add a value to the waste. A challenge is to identify the hazardous waste treatment options and select the best option in view of the risks, effectiveness and costs associated these options. The hazardous waste risk management framework is represented as in Figure 2.

\section{Literature Review}

There has been a growing body of literature in the area of risk-based decision analysis on hazardous waste. Combining the risk analysis with the variety of other aspects of hazardous waste management, many studies make use of decision analysis methodologies by which the technical issues and non-technical issues such as cost and effectiveness are considered.

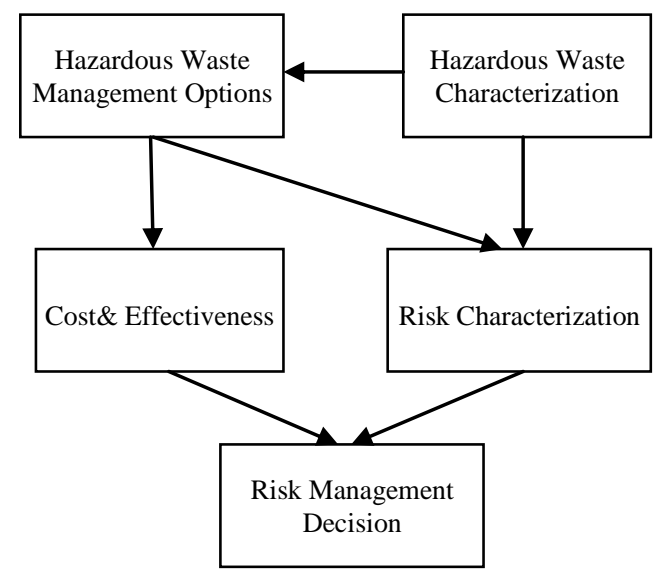

Fig. 2. Hazardous waste risk management framework

A systematic and consistent decision making approach to dredging and disposal including contaminated sediment management have been developed in Ref. 5 . They have identified and evaluated environmentally acceptable and cost-effective disposal alternatives within an effective decision making framework for costs, risk reduction and potential beneficial uses of the disposal material. They have considered tree alternatives, deepwater confined disposal, near shore fill or capping and, upland disposal in the presented hypothetical disposal scenario and adopted a risk-cost trade off approach in making decisions. Their approach entails the performance of sequential evaluations consisting of risk analysis, estimation of costs, integration of the results into a computational framework for trade-off analysis, and the application of decision analytical tools to build consensus among stakeholders and the general public in selecting a preferred alternative.

The decision problems related to hazardous waste management system have been investigated by many approaches including mathematical models in the search for an optimal strategy. A multi-objective integer programming approach to select hazardous waste 
treatment and disposal facilities, and transportation routes have been employed in Ref. 6 They searched the best alternatives for two objectives; minimization of total cost, which includes treatment and disposal costs (sum of the capital cost, operation and maintenance cost of the treatment and disposal facilities), and transportation cost as well as minimization of total risk, which includes waste treatment and disposal risk as well as risk involved in waste transportation. They aimed to find the optimal location of treatment and disposal facilities, waste quantities traveling on the transportation links and waste quantities being processed at the treatment or disposal facilities under the constraints such as waste-technology compatibility, allowable capacities for treatment and disposal technologies at specific sites, etc. Finally, they presented an example problem to perform sensitivity analysis in order to study the effect of change in the preferences of the objectives in the utility function and the weightings given to the objectives.

Radioactive waste attracts a special consideration in hazardous waste literature. In this research stream, Ref. 7 proposed a decision support system for the identification of optimal remedial strategies to restore water systems after accidental introduction of radioactive substances. This decision support system includes an evaluation module based on a multiattribute value model to rank alternatives and a module to perform multi-parametric sensitivity analyses, both with respect to weights and values, to allow us to gain insights into the problem. Ref. 8 used this decision support system in their study searching for optimum remedial strategies for contaminated lakes.

One can deduce from Ref. 9 the use of multicriteria decision analysis with an outranking methodology, Promethee. This tool allowed them to incorporate stakeholder values into the decision process for soliciting public participation and analyze technological hazardous waste management alternatives with the option to introduce new alternatives at any point during the analysis. The use of Promethee was chosen also due its capability of handling semiquantitative scales (e.g., high, middle, low) compared to other optimization methods such as multiattribute utility theory (MAUT) or analytical process hierarchy (AHP).

A review of existing decision-making approaches at hazardous waste management regulatory agencies in the United States and Europe is presented in Ref.10. The study synthesizes state-of-the-art research in multi criteria decision analysis (MCDA) methods in this area. They also tested an MCDA approach, Promethee, for coupling expert judgment and stakeholder values in a hypothetical contaminated sediments management case study.

The hazards of contaminated dredged material disposal and the associated risks and costs which are highly uncertain have been incorporated in the decision analysis using fuzzy set theory ${ }^{11}$. By this means, these uncertainties and the risk-cost trade-offs are explicitly considered selecting an appropriate management alternative in the proposed multicriteria decision framework.

A crisp and a fuzzy approach which are applied in dam safety and nuclear industries for risk-based decision analysis are investigated in Ref. 12. One of the approaches is the structured explicit decision analysis, in the case of dam safety, which develops consistency to a complex decision problem through simplification. The major decision objectives and goals, which are summarized in regulatory compliance, risk control, and cost-effectiveness, are used to structure the process. The structured process needs to: (a) satisfy regulatory standards, (b) identify actions and measures to control life-loss and economic risks, and (c) evaluate costs and cost-effectiveness to justify, rank, select, and prioritize actions. The second approach which is used in the case of the utility and nuclear industries is the implicit multicriteria decision analysis. The proposed decision process requires the identification of the decision criteria relevant to the problem in hand, and the specification of the relative importance of the criteria by means of value eliciting from managers or stakeholders. After that, decision alternatives are scored against the decision criteria and then ranked based on the multiattribute theory. This approach commonly employs ranking schemes as fuzzy logic and heuristic methods.

One can infer from Ref. 13 the use of the approaches investigated in their former paper for the management of contaminated ground water resources problem. They used health risk assessment and economic analysis through a multi-criteria decision analysis framework to select the best remedial alternative. The decision criteria set included maximum individual risk, expected individual risk, population risk, risk index, and cost per cancer case avoided or cost per life saved. Three potential approaches were investigated for alternative 
ranking, a structured explicit decision analysis, a heuristic approach of importance of the order of criteria, and a fuzzy logic approach based on fuzzy dominance and similarity analysis.

\section{Hazardous Waste Treatment Methods}

The objective of waste treatment is to modify the physical and/or chemical properties of the waste to make it suitable for safe disposal ${ }^{4}$. Treatment methods are often used prior to ultimate disposal of the hazardous wastes. The treatment technologies convert the waste into a more innocuous form, or immobilize toxic components so that it will not migrate and present a hazard when released into the environment. Treatment technologies are characterized by their effectiveness to treat specific waste types, their waste residue generation factor, the cost and the risk considerations associated with them ${ }^{14}$.

The hazardous waste treatment processes may be classified in four main groups:

(i) Physical treatment processes

(ii) Chemical treatment processes

(iii) Thermal treatment processes

(iv) Biological treatment processes particle size or relative density. The physical separation processes are often applied for the primary purpose of isolating components of a waste for recovery. In the context of final disposal, separation is useful to reduce the quantity or hazardousness of the residue and simplify the process. Some of the separation methods such as filtration, centrifuging, sedimentation, etc. depend on different physical principles or different phase of wastes such as solid waste or liquid waste. Encapsulation is also a physical treatment method by which hazardous wastes are converted into a form designed to prevent or significantly reduce release into the environment. Hazardous materials are immobilized by stabilization and incorporation within a solid matrix such as cement concrete or proprietary organic polymers. It is commonly used prior to land filling.

By chemical treatment methods, the chemical structure of the hazardous waste material is converted into substances which have no or less hazardous properties. The process may be described as the alteration of the chemical nature/structure of the hazardous constituents of a waste using chemical reactions. Some of the chemical treatment processes and the common elements used in these processes are illustrated as follows:

neutralization occurs by the reaction of the waste acid

Table 2. Hazardous waste treatment methods ${ }^{4}$.

\begin{tabular}{|c|c|c|c|c|}
\hline \multicolumn{3}{|l|}{$\begin{array}{l}\text { Physical treatment } \\
\text { processes }\end{array}$} & \multirow[t]{2}{*}{$\begin{array}{l}\text { Chemical treatment } \\
\text { processes }\end{array}$} & \multirow[t]{2}{*}{$\begin{array}{l}\text { Biological treatmen } \\
\text { processes }\end{array}$} \\
\hline Gas cleaning & $\begin{array}{l}\text { Liquid solids } \\
\text { separation }\end{array}$ & $\begin{array}{l}\text { Removal of scientific } \\
\text { components }\end{array}$ & & \\
\hline Mechanical collection & Centrifugation & Adsorption & Adsorption & Activated sludge \\
\hline $\begin{array}{l}\text { Electrostatic } \\
\text { precipitation }\end{array}$ & Clarification & Crystallization & Chemical oxidation & Aerobic lagoons \\
\hline Fabric filter & Coagulation & Dialysis & Chemical precipitation & Spray irrigation \\
\hline Wet scrubbing & Filtration & Distillation & Chemical reduction & Trickling filters \\
\hline $\begin{array}{l}\text { Activated carbon } \\
\text { adsorption }\end{array}$ & Flocculation & Electrodialysis & $\begin{array}{l}\text { Combination and } \\
\text { addition }\end{array}$ & $\begin{array}{l}\text { Waste stabilization } \\
\text { ponds }\end{array}$ \\
\hline \multirow[t]{5}{*}{ Adsorption } & Floating & Evaporation & Ion exchange & \\
\hline & Foaming & Leaching & Neutralization & \\
\hline & Sedimentation & Reverse osmosis & Pyrolysis & \\
\hline & Thickening & Solvent extraction & & \\
\hline & & Stripping & & \\
\hline
\end{tabular}

Various methods are used under these three groups of treatment processes. Some of them are listed in Table 2. By physical treatment methods, a waste is often separated into its constituents. The principle of separation is related to a physical property such as with an alkali, oxidation is started with common oxidizing substances such as hydrogen peroxide or calcium hypochlorite, reduction is used to convert inorganic substances to a less mobile and toxic form by the use of chemicals, hydrolysis is the decomposition of 
hazardous organic substances typically (e.g. decomposing certain pesticides with sodium hydroxide), ion exchange removes dissolved salts primarily inorganics from aqueous solutions, precipitation is mainly used to convert hazardous heavy metals to a less mobile, insoluble form. A commonly-used treatment method which may also be classified as a chemical process is combustion.

Thermal treatment which is generally named as combustion is the reaction of hazardous wastes with oxygen sometimes in the presence of an external energy source. If the waste material is completely organic in structure, it is, in theory, completely destructible using principles based in thermodynamics. Energy may also be produced during the reaction and the heat may be recovered. However, in combustion potentially more risky off-gases containing chlorinated hydrocarbons and/or ashes containing heavy metals are produced ${ }^{1}$.

By biological treatment processes, certain compounds of waste substances are broken down by miocroorganism based activities through metabolism to provide nutrient energy or through co-metabolism. Effective processing depends on selecting a microorganism suitable for the species requiring treatment, and on carrying out the treatment under conditions which are suitable, including careful control of the nature and composition of the waste. Generally, biological processes destruct the organic wastes in theory and have little effect on inorganic wastes including metals, although some absorption into a sludge phase may occur with some processes. Another issue is that biological processes become less efficient as concentrations of treatable constituents diminish ${ }^{15}$. During all treatment processes, the input waste must be monitored and possibly controlled also to maintain environmental conditions that do not upset or destroy the microorganisms in the system. Some of the monitoring and control requirements for each of the systems include temperature, $\mathrm{pH}$, oxygen availability, additional food sources, etc. ${ }^{1}$. The various biological processes fall into two main categories; aerobic processes in which the presence of oxygen is necessary, and those operating in oxygen free conditions, known as anaerobic processes ${ }^{15}$.

\section{Risk Assessment Criteria}

It is essential to identify the decision objectives and the set of comprehensive and non-redundant criteria corresponding to the objectives in decision analysis. The immediate objectives in hazardous waste management typically include reducing the risks and minimizing the costs. Technical efficiency may also be included in the objectives with an attention on the hazardous waste treatments.

The criteria corresponding to the objectives have been specified as the capital costs, operations and maintenance costs, land costs, waste-treatment technology compatibility, efficiency of offsetting hazard potential, pollutant removal efficiency, human health risks, ecological risks and transportation risks.

Capital costs: This criterion includes the economical amount of the first investment for the facility and the technology.

Operation and maintenance costs: This criterion represents the total operation and annual costs per treated waste.

Land costs: This criterion takes into account the economic value of the land needed for the hazardous waste management system based on the size of the area and the placement of the land with respect to its distance to the city center.

Waste-Treatment technology compatibility: This criterion refers to the consideration of compatibility between the technology and different waste types.

Efficiency of offsetting hazard potential: This criterion includes the degree waste management system eliminates the hazardousness of the waste.

Waste residue: This criterion represents the amount of waste generated as a result of the waste treatment.

Resource recovery: This criterion stands for the amount of value (e.g. output energy, recovered waste, etc.) that can be recovered from the waste.

Capacity: This criterion refers to amount of waste which the hazardous waste management system is able to treat. Human health risks: This criterion consists of risks associated with the hazardous substances such as emission levels and heavy metal released to air, water or land affecting human health.

Ecological risks: This criterion infers to the risks associated with the hazardous substances such as emission levels and heavy metal released to air, water or land affecting the ecosystem and causing loss of important habitats, decreases in the size of the population of sensitive species.

Transportation risk: This criterion covers the total transport risk imposed on the public and the 
environment by the movement of the hazardous waste between locations such as generation, collection, storage, treatment and disposal locations.

\section{Fuzzy MultiCriteria Assessment}

VIKOR initiated by Ref.16, of which the compromise solution should have a maximum group utility (majority rule) and minimum individual regret of the opponent, is proposed to deal with multicriteria decision-making problems. VIKOR method is based on the compromise programming of MCDM. The method works on the principle that each alternative is evaluated by each criterion function; the compromise ranking is presented by comparing the degree of closeness to the ideal alternative ${ }^{17}$.

In fuzzy VIKOR, it is suggested that decision makers use linguistic variables to evaluate the ratings of alternatives with respect to the criteria. Fuzzy set theory uses approximate information and uncertainty to generate decisions. This makes it favorable for human reasoning, intuition, judgment, perception and preference which are generally vague and difficult to measure. Since knowledge about real-world problems, which has imprecision in the variables and parameters, can be expressed by fuzzy sets, many engineering and decision problems have been simplified and processed using fuzzy techniques. A fuzzy approach has been applied to classical VIKOR to capture the imprecision in the evaluations of the decision makers. The use of fuzzy VIKOR is summarized in steps as follows ${ }^{18,19}$ :

Step 1: A group of decision-makers (denoted with $\mathrm{k}$ ) identifies the evaluation criteria (denoted with $\mathrm{n}$ ) and the alternatives (denoted with $\mathrm{m}$ ).

Step 2: Appropriate linguistic variables for the weights of the criteria and alternative ratings are chosen. Examples of linguistic variables corresponding to fuzzy scores are given in Table 3 and 4. These triangular fuzzy numbers with their membership values are illustrated in Figures 3 and 4.

Table 3. Fuzzy evaluation scores for the weights

\begin{tabular}{ll}
\hline Linguistic variable & Fuzzy score \\
\hline Very Low & $(0.0,0.1,0.2)$ \\
Low & $(0.1,0.2,0.4)$ \\
Medium & $(0.3,0.5,0.7)$ \\
High & $(0.6,0.8,0.9)$ \\
Very High & $(0.8,0.9,1.0)$ \\
\hline
\end{tabular}

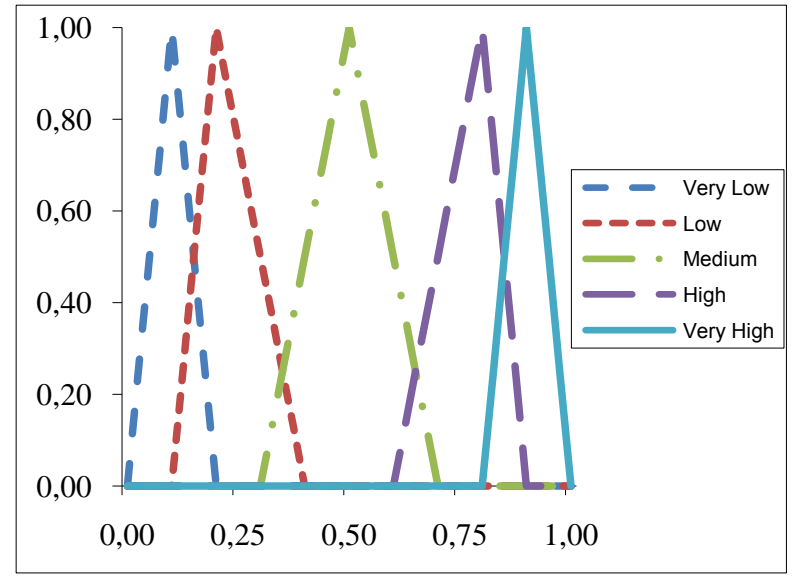

Fig.3. The triangular fuzzy weights.

Table 4. Fuzzy scores for the alternative ratings.

\begin{tabular}{ll}
\hline Linguistic variable & Fuzzy score \\
\hline Very Poor & $(0,0,1)$ \\
Poor & $(0,1,3)$ \\
Medium Poor & $(1,3,5)$ \\
Fair & $(3,5,7)$ \\
Medium Good & $(5,7,9)$ \\
Good & $(7,9,10)$ \\
Very Good & $(9,10,10)$ \\
\hline
\end{tabular}

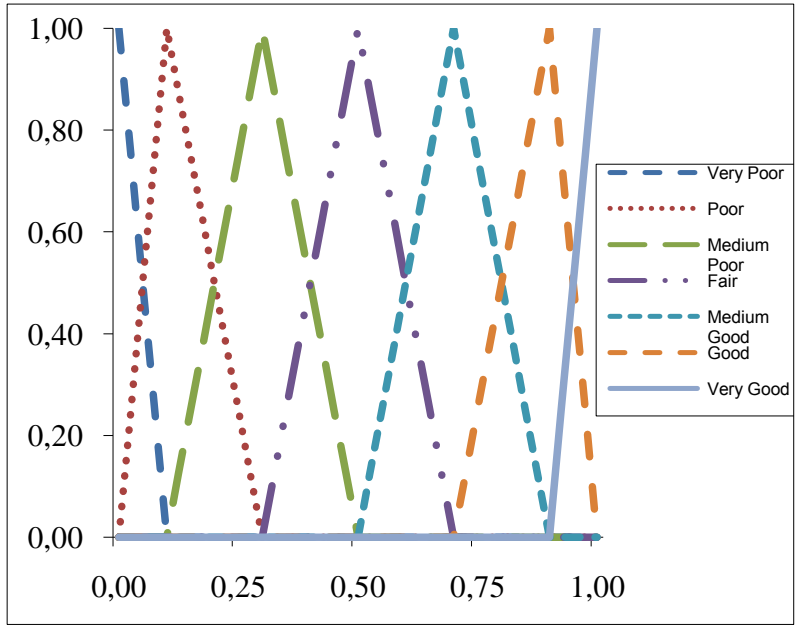

Fig. 4. The triangular fuzzy scores for alternative ratings.

Step 3: The linguistic evaluations of the decision makers are collected to calculate the aggregated fuzzy weights of the criteria, and aggregated fuzzy rating of alternatives.

$$
\widetilde{w}_{j}=\frac{1}{K}\left[\widetilde{w}_{j}^{1} \oplus \widetilde{w}_{j}^{2} \oplus \ldots \oplus \widetilde{w}_{j}^{K}\right]
$$




$$
\tilde{x}_{i j}=\frac{1}{K}\left[\tilde{x}_{i j}^{1} \oplus \tilde{x}_{i j}^{2} \oplus \ldots \oplus \tilde{x}_{i j}^{K}\right]
$$

Step 4: Fuzzy decision matrix is constructed for the implementation of VIKOR. A fuzzy multicriteria decision making problem can be expressed in matrix format as follows:

$$
\begin{gathered}
\tilde{D}=\left[\begin{array}{cccc}
\tilde{x}_{11} & \tilde{x}_{12} & \ldots & \tilde{x}_{1 n} \\
\tilde{x}_{21} & \tilde{x}_{22} & \ldots & \tilde{x}_{21} \\
\vdots & \vdots & \ddots & \vdots \\
\tilde{x}_{m 1} & \tilde{x}_{m 1} & \cdots & \tilde{x}_{m n}
\end{array}\right] \\
\tilde{W}=\left[\tilde{w}_{1}, \tilde{w}_{2}, \ldots, \tilde{w}_{n}\right]
\end{gathered}
$$

Step 5: Fuzzy best value (FBV; $\tilde{f}_{j}^{*}$ ) and fuzzy worst value (FWV; $\left.\tilde{f}_{j}\right)$ of each criterion function are determined.

$$
\begin{gathered}
\tilde{f}_{j}^{*}=\max _{i} \tilde{x}_{i j}, j \in B \\
\tilde{f}_{j}=\min _{i} \tilde{x}_{i j}, j \in C
\end{gathered}
$$

Step 6: Separation measures $\tilde{S}_{i}$ and $\tilde{R}_{i}$ are calculated.

$$
\begin{gathered}
\tilde{S}_{i}=\sum_{j-1}^{n} \tilde{w}_{j}\left(\tilde{f}_{j}^{*}-\tilde{x}_{i j}\right) /\left(\tilde{f}_{j}^{*}-\tilde{f}_{j}\right) \\
\tilde{R}_{i}=\max _{j}\left\lfloor\tilde{w}_{j}\left(\tilde{f}_{j}^{*}-\tilde{x}_{i j}\right) /\left(\tilde{f}_{j}^{*}-\tilde{f}_{j}\right)\right\rfloor
\end{gathered}
$$

Step 7: $\tilde{Q}_{i}$ values are calculated.

$$
\tilde{Q}_{i}=v\left(\tilde{S}_{i}-\tilde{S}^{*}\right) /\left(\tilde{S}^{-}-\tilde{S}^{*}\right)+(1-v)\left(\tilde{R}_{i}-\tilde{R}^{*}\right) /\left(\tilde{R}^{-}-\tilde{R}^{*}\right)
$$
such that,

$$
\begin{array}{ll}
\tilde{S}^{*}=\min _{i} \tilde{S}_{i}, & \tilde{S}^{-}=\max _{i} \tilde{S}_{i} \\
\tilde{R}^{*}=\min _{i} \tilde{R}_{i}, & \tilde{R}^{-}=\max _{i} \tilde{R}_{i}
\end{array}
$$

$\tilde{S}^{*}$ is the maximum majority rule, and $\widetilde{R}^{*}$ is the minimum individual regret of an opponent strategy. As well, $v$ is introduced as weight of the strategy of the maximum group utility, usually set as $v=0.5$.

Step 8: $\tilde{Q}_{i}$ values are defuzzified and the alternatives are ranked by the index $\widetilde{Q}_{i}$.

Various defuzzification strategies have been suggested in the literature. Here we have chosen to use the graded mean integration approach is used ${ }^{20}$. According to the graded mean integration approach, for triangular fuzzy numbers, a fuzzy number $\widetilde{C}=\left(c_{1}, c_{2}, c_{3}\right)$ can be transformed into a crisp number by employing the below equation:

$$
C=\frac{c_{1}+4 c_{2}+c_{3}}{6}
$$

Step 9: The best alternative is determined as the one with the minimum $Q_{i}$.

\section{Application}

The city of Istanbul and the area close to Istanbul is the most industrialized area in Turkey. As expected, this area also serves as an inhabitation area for the highest portion of the population in Turkey. Thus, the hazardous waste resulting from the industry and high population density make up a considerably high amount. However, the facilities for the treatment of hazardous waste are very limited or almost not available in this area. The limited number of hazardous waste treatment facilities is not enough to treat the amount and the types of the hazardous waste generated presently.

In Turkey, the industrial waste amount was stated to be 12,5 million tons, of which 1,14 million tons were in the category of hazardous waste in $2008^{21}$. The hazardous waste amount for the European part of Istanbul and three neighboring cities, Tekirdag, Edirne and Kirklareli was estimated to be 160.000 tons/year in 2007. This amount has been envisioned to increase to 180.000 tons/year in 2010 by Ministry of Environment in the Action Plan for 2008-2012. The distribution of the hazardous waste types for the European part of Istanbul and the cities Tekirdag, Kirklareli and Edirne is given in Table 5.

The hazardous waste generated in the Asian part of Istanbul and the neighboring city Izmit which is also a highly industrialized area is mainly treated in the treatment facility located in Izmit. This facility treats the hazardous waste by combustion with a burning capacity of 35.000 tons/year and storage capacity of 160.000 tons/year.

In spite of the high amount of hazardous waste generated in Istanbul, the capacity and the types of treatment technologies available in this area are very limited and scarce. Hazardous waste treatment facilities are required in the areas such as Istanbul which are 
highly industrialized with high density of population for both the minimization of the costs and stress on human health and ecology. There has been considerable attention on the need for additional treatment facilities and plans have been generated for fulfilling this need. However, it is important to decide which treatment technologies is adequate based on the waste types and quantities generated, the risks associated with these waste and the economical perspectives of the treatment technologies. We propose to use a MCDM, fuzzy VIKOR as presented in Section 6, for the decision making of treatment methods for Istanbul area.

The treatment method alternatives for Istanbul are identified as the ones explained in Section 4. These alternatives include:

- Physical treatment $\left(\mathrm{T}_{1}\right)$

- Chemical treatment $\left(\mathrm{T}_{2}\right)$

- Thermal treatment (combustion) $\left(\mathrm{T}_{3}\right)$
- Biological treatment $\left(\mathrm{T}_{4}\right)$

- No treatment (direct disposal, e.g. land filling) $\left(\mathrm{T}_{5}\right)$

The objectives of the decision making for treatment methods are identified as minimization of costs and risks and maximization of technical efficiency. Thus, the criteria corresponding to the economic objectives are determined as capital costs $\left(\mathrm{C}_{1}\right)$, operation and maintenance costs $\left(C_{2}\right)$ and land costs $\left(C_{3}\right)$. The risk criteria are specified as human health risks $\left(\mathrm{C}_{4}\right)$, ecological risks $\left(\mathrm{C}_{5}\right)$ and transportation risks $\left(\mathrm{C}_{6}\right)$.

The technical criteria are represented by wastetreatment technology compatibility $\left(\mathrm{C}_{7}\right)$, efficiency of offsetting hazard potential $\left(\mathrm{C}_{8}\right)$, waste residue $\left(\mathrm{C}_{9}\right)$, resource recovery $\left(\mathrm{C}_{10}\right)$ and capacity $\left(\mathrm{C}_{11}\right)$. These criteria were explained in detail in Section 5 and listed in Table 6.

Table 5. The distribution of the hazardous waste in the European part of Istanbul, Tekirdag, Kirklareli, Edirne cities

\begin{tabular}{|c|c|c|c|c|c|c|}
\hline \multirow[b]{2}{*}{ Waste Types } & \multicolumn{6}{|c|}{ Amount (tons/year) } \\
\hline & Tekirdag & Kırklareli & Edirne & Istanbul & $\begin{array}{c}\text { Total } \\
\text { (4 Cities) }\end{array}$ & $\begin{array}{c}\text { Total } \\
\text { (Turkey) }\end{array}$ \\
\hline Pesticide and Agrochemical Waste & 58 & 45 & 34 & 582 & 719 & 5926 \\
\hline Wood Protectors & 24 & 0 & 5 & 232 & 261 & 1780 \\
\hline Leather Industry Waste & 2884 & 312 & 552 & 9619 & 13367 & 31739 \\
\hline Oil Refinery Waste & 361 & 0 & 19 & 3033 & 3413 & 65631 \\
\hline Acids and Alkali Waste & 1970 & 75 & 1289 & 14538 & 17872 & 62477 \\
\hline Hazardous Inorganic Chemical Waste & 1071 & 15 & 903 & 15003 & 16992 & 48646 \\
\hline Hazardous Organic Chemical Waste & 7364 & 229 & 4380 & 54064 & 66037 & 212870 \\
\hline Dye and Glue Production Waste & 1381 & 100 & 216 & 15583 & 17280 & 54719 \\
\hline Hazardous Waste of Printing Processes & 144 & 5 & 26 & 2543 & 2718 & 4908 \\
\hline Energy Production Hazardous Waste & 1568 & 0 & 3419 & 392 & 5379 & 32531 \\
\hline Metal Production Hazardous Waste & 4221 & 3 & 741 & 28424 & 33389 & 114586 \\
\hline Mineral and Glass Production Hazardous Waste & 304 & 76 & 375 & 2157 & 2912 & 18983 \\
\hline Hazardous Waste of Galvanizing Processes & 952 & 21 & 77 & 13858 & 14908 & 44763 \\
\hline Non-Halogen Waste Oils & 3207 & 721 & 880 & 49758 & 54566 & 208344 \\
\hline Waste Oils with halogen & 42 & 6 & 19 & 507 & 574 & 2466 \\
\hline Waste Oils with Emulsion & 967 & 279 & 291 & 17876 & 19413 & 80075 \\
\hline Other Waste Oils & 708 & 139 & 170 & 12331 & 13348 & 53266 \\
\hline Solvent Waste with halogen & 222 & 20 & 30 & 3312 & 3584 & 12228 \\
\hline Solvent Waste without halogen & 752 & 65 & 110 & 10211 & 11138 & 36059 \\
\hline Contaminated Packaging Waste & 1177 & 115 & 546 & 11689 & 13527 & 48235 \\
\hline Used Filters and Absorbands & 646 & 135 & 269 & 7319 & 8369 & 32859 \\
\hline Used Oil Filters & 35 & 10 & 12 & 572 & 629 & 2507 \\
\hline Used Brake Oils and Antifreeze & 36 & 28 & 21 & 784 & 869 & 3971 \\
\hline Waste Batteries & 471 & 324 & 262 & 9282 & 10339 & 47613 \\
\hline Used Catalysts & 3 & 0 & 1 & 20 & 24 & 180 \\
\hline Physiochemical treatment sludge & 1434 & 63 & 177 & 26276 & 27950 & 99433 \\
\hline Contaminated Mercury Waste & 64 & 14 & 19 & 512 & 609 & 2398 \\
\hline Contaminated Wood & 219 & 119 & 100 & 3772 & 4210 & 21176 \\
\hline Total & 32285 & 2919 & 14943 & 314249 & 364396 & 1350369 \\
\hline
\end{tabular}


After determining the evaluation criteria and the alternatives, the steps of the fuzzy VIKOR are employed. Evaluations of three decision maker are used in the analysis. In order to determine the importance of each treatment decision criterion and the ratings of the alternatives with respect to the criteria, decision makers used the five point scale and the seven point scale given respectively in Table 2 and 3.

Table 6. List of evaluation criteria.

\begin{tabular}{ll}
\hline Aspects & Criteria \\
\hline Economic & Capital costs \\
& Operation and maintenance costs \\
& Land costs \\
Risks & Human health risks \\
& Ecological risks \\
& Transportation risks \\
Technical & Waste-treatment technology compatibility \\
& Efficiency of offsetting hazard potential \\
& Waste residue \\
& Resource recovery \\
& Capacity \\
\hline
\end{tabular}

The evaluations of decision makers for the weight importance and the overall fuzzy weights of each criterion of which are calculated according to Eq. (1) are given in Table 7 .
Table 7. Evaluations of decision makers for criteria and the overall fuzzy weight of each criterion.

\begin{tabular}{lllll}
\hline & DM1 & DM2 & DM3 & Overall Weight \\
\hline $\mathrm{C}_{1}$ & $\mathrm{~L}$ & $\mathrm{VL}$ & $\mathrm{M}$ & $(0.13,0.26,0.43)$ \\
$\mathrm{C}_{2}$ & $\mathrm{~L}$ & $\mathrm{~L}$ & $\mathrm{VL}$ & $(0.06,0.16,0.33)$ \\
$\mathrm{C}_{3}$ & $\mathrm{VL}$ & $\mathrm{VL}$ & $\mathrm{VL}$ & $(0,0.1,0.2)$ \\
$\mathrm{C}_{4}$ & $\mathrm{VH}$ & $\mathrm{VH}$ & $\mathrm{H}$ & $(0.73,0.86,0.96)$ \\
$\mathrm{C}_{5}$ & $\mathrm{M}$ & $\mathrm{H}$ & $\mathrm{H}$ & $(0.5,0.7,0.83)$ \\
$\mathrm{C}_{6}$ & $\mathrm{VH}$ & $\mathrm{H}$ & $\mathrm{H}$ & $(0.66,0.83,0.93)$ \\
$\mathrm{C}_{7}$ & $\mathrm{VH}$ & $\mathrm{VH}$ & $\mathrm{VH}$ & $(0.8,0.9,1)$ \\
$\mathrm{C}_{8}$ & $\mathrm{VH}$ & $\mathrm{VH}$ & $\mathrm{VH}$ & $(0.8,0.9,1)$ \\
$\mathrm{C}_{9}$ & $\mathrm{M}$ & $\mathrm{H}$ & $\mathrm{L}$ & $(0.33,0.5,0.66)$ \\
$\mathrm{C}_{10}$ & $\mathrm{M}$ & $\mathrm{L}$ & $\mathrm{M}$ & $(0.23,0.4,0.6)$ \\
$\mathrm{C}_{11}$ & $\mathrm{H}$ & $\mathrm{H}$ & $\mathrm{VH}$ & $(0.66,0.83,0.93)$ \\
\hline
\end{tabular}

Next step is to gather the decision makers' ratings for the treatment alternative with respect to each criterion. Then, these ratings are aggregated into an overall rating according to Eq. (2). Using these overall ratings, the decision matrix is constructed as given in Table 8 .

Then, separation measures from the fuzzy best value $\tilde{S}_{i}$ and the fuzzy worst value $\widetilde{R}_{i}$ are computed using Eq (3) and (4). These values are given in Table 9.

Table 8. Fuzzy evaluation matrix for the given treatment alternatives.

\begin{tabular}{llllll}
\hline & $\mathrm{T}_{1}$ & $\mathrm{~T}_{2}$ & $\mathrm{~T}_{3}$ & $\mathrm{~T}_{4}$ & $\mathrm{~T} 5$ \\
\hline $\mathrm{C}_{1}$ & $(8.3,9.6,10)$ & $(6.3,8.3,9.6)$ & $(2.3,4.3,6.3)$ & $(3,5,7)$ & $(5.6,7.6,9.3)$ \\
$\mathrm{C}_{2}$ & $(7,8.6,9.6)$ & $(5.6,7.6,9.3)$ & $(7.6,9,9.6)$ & $(0,0.3,1.6)$ & $(8.3,9.6,10)$ \\
$\mathrm{C}_{3}$ & $(2,3.6,5.6)$ & $(3,5,7)$ & $(7.6,9.3,10)$ & $(4.3,6.3,8.3)$ & $(5,7,8.6)$ \\
$\mathrm{C}_{4}$ & $(0.3,1.3,3)$ & $(5,7,8.6)$ & $(2.3,4.3,6.3)$ & $(8.3,9.6,10)$ & $(0,0,1)$ \\
$\mathrm{C}_{5}$ & $(0,0.3,1.6)$ & $(4.3,6.3,8.3)$ & $(0,0.6,2.3)$ & $(8.3,9.6,10)$ & $(0,0.3,1.6)$ \\
$\mathrm{C}_{6}$ & $(3,5,7)$ & $(0.3,1.3,3)$ & $(1.3,3,5)$ & $(6.3,8.3,9.6)$ & $(0,0.3,1.6)$ \\
$\mathrm{C}_{7}$ & $(7.6,9.3,10)$ & $(4.3,6.3,8.3)$ & $(8.3,9.6,10)$ & $(0.3,1.6,3.6)$ & $(5.6,7.6,9)$ \\
$\mathrm{C}_{8}$ & $(0.3,1.3,3)$ & $(5,7,8.6)$ & $(3,5,7)$ & $(5.6,7.6,9.3)$ & $(0,0,1)$ \\
$\mathrm{C}_{9}$ & $(2.3,4.3,6.3)$ & $(5,7,8.6)$ & $(8.3,9.6,10)$ & $(3,5,7)$ & $(0,0,1)$ \\
$\mathrm{C}_{10}$ & $(3.6,5.6,7.6)$ & $(2.3,4.3,6.3)$ & $(7.6,9.3,10)$ & $(5,7,8.6)$ & $(0,0.3,1.6)$ \\
$\mathrm{C}_{11}$ & $(3,5,7)$ & $(5,7,8.6)$ & $(8.3,9.6,10)$ & $(0,1,3)$ & $(6.3,8.3,9.6)$ \\
\hline
\end{tabular}


Table 9. Separation measures of treatment alternatives from the fuzzy best and fuzzy worst values.

\begin{tabular}{lll}
\hline & \multicolumn{1}{c}{$\tilde{S}_{i}$} & \multicolumn{1}{c}{$\tilde{R}_{i}$} \\
\hline $\mathrm{T}_{1}$ & $(3.16,3.56,3.69)$ & $(0.75,0.74,0.83)$ \\
$\mathrm{T}_{2}$ & $(2.26,2.43,2.19)$ & $(0.62,0.72,0.76)$ \\
$\mathrm{T}_{3}$ & $(2.05,2.28,2.41)$ & $(0.52,0.67,0.76)$ \\
$\mathrm{T}_{4}$ & $(1.92,2.51,3.00)$ & $(0.8,0.9,1)$ \\
$\mathrm{T}_{5}$ & $(3.73,4.67,5.33)$ & $(0.8,0.9,1)$ \\
\hline
\end{tabular}

After that, $\tilde{S}^{*}, \tilde{S}^{-}, \tilde{R}^{*}$ and $\tilde{R}^{-}$are calculated in order to compute the $\widetilde{Q}_{i}$ using Eq. (5). The value of $\mathrm{v}$ in this equation is taken as 0.5 . The last step is to defuzzify the $\tilde{Q}_{i}$ values using Eq. (6) and then rank the alternatives based on the $Q_{i}$ index values. Table 10 gives the results of the fuzzy VIKOR analysis.

Table 10. Fuzzy VIKOR analysis results for hazardous waste treatment method selection.

\begin{tabular}{llll}
\hline & \multicolumn{1}{c}{$\tilde{Q}_{i}$} & $Q_{i}$ & $\begin{array}{c}\text { Rank } \\
\text { Order }\end{array}$ \\
\hline $\mathrm{T}_{1}$ & $(0.38,0.41,0.75)$ & 0.47 & 3 \\
$\mathrm{~T}_{2}$ & $(0,0.14,0.27)$ & 0.14 & 2 \\
$\mathrm{~T}_{3}$ & $(0,0.035,0.036)$ & 0.03 & 1 \\
$\mathrm{~T}_{4}$ & $(0.5,0.55,0.63)$ & 0.55 & 4 \\
$\mathrm{~T}_{5}$ & $(1,1,1)$ & 1.00 & 5 \\
\hline
\end{tabular}

According to the crisp $Q_{i}$ values, the ranking of the alternatives is found to be $T_{3}, T_{2}, T_{1}, T_{4}$ and $T_{5}$. The best alternative is identified as $\mathrm{T}_{3}$ by which thermal treatment methodologies (combustion) was denoted. The second best treatment methodology is concluded as $\mathrm{T}_{2}$, which is representing the chemical treatment. And the ranking order follows as $T_{1}$, physical treatment, $T_{4}$ biological treatment and $\mathrm{T}_{5}$ no treatment but directly disposal.

\section{Conclusion}

In today's industrialized world, hazardous waste is inevitable however it poses a high risk if it is not managed properly. Hazardous waste risk range from toxic risks including the probability of a certain population have a particular illness to other risks such as ecosystem stress, loss of important habitats, public safety and public welfare hazards. Thus, the ultimate goal to manage hazardous waste safely from the moment it is generated; while it is transported, treated, or stored; until the moment it is disposed with the minimum cost.

Turkey is a developing country with a high industry growth and high population. However, the attention given to hazardous waste management is not sufficient. The first hazardous waste management controlling directive was announced 25 years ago. And yet, hazardous waste management activities have not been organized effectively to fulfill the need for dealing with the generated waste types and amounts. Therefore, we have proposed a fuzzy VIKOR multicriteria decision analysis for the selection of the most appropriate hazardous waste treatment methodology. Then, an application was presented to show the potential of the proposed methodology for the case of Istanbul.

In the application problem was designed to select among the physical, chemical, thermal, biological treatment processes or a disposal option without any treatment process. The alternatives were evaluated with respect to eleven criteria. The results of the decision analysis which was based on the evaluations of three experts from Istanbul suggest that combustion is the treatment alternative which fits Istanbul's hazardous waste management needs best. The treatment methods to be considered next in an order are concluded as chemical treatment, physical treatment and biological treatment. The last option for hazardous waste to be considered is found to be direct disposal without any treatment.

In the future research, similar studies can be conducted for the selection of specialized treatment methodologies which are appropriate for specific waste groups. Besides, the problems may be solved by different multi-criteria decision-making methodologies such as fuzzy PROMETHEE, fuzzy ELECTRE or fuzzy TOPSIS. 


\section{References}

1. Vallero, D.A. and Peirce, J.J., Engineering the Risks of Hazardous Wastes (Butterworth-Heinemann Publications Elsevier Science, MA, 2003).

2. Shammas N.K., Characteristics of Hazardous Industrial Waste, in Handbook of Advanced Industrial and Hazardous Wastes Treatment, eds. Wang L.K., Hung, Y.T., Shammas N.K. (CRC Press, Florida, 2010), pp.485517.

3. Cheremisinoff N.P. and Cheremisinoff P.N., Hazardous Materials And Waste Management: A Guide for the Professional Hazards Manager (Noyes Publications, New Jersey, 1995).

4. Misra V., Pandey S.D., Hazardous waste, impact on health and environment for development of better waste management strategies in future in India, Environment International, 31 (2005) 417- 431.

5. Pavlou, S. P., \& Stansbury, J. S., Risk-cost trade off considerations for contaminated sediment disposal, Human and Ecological Risk Assessment, 4(4) (1998) 991-1002.

6. Nema A.K. and Gupta, S.K., Optimization of regional hazardous waste management systems: an improved formulation, Waste Management 19 (1999) 441-451.

7. Insua, D. R., Galleqo, E., Mateos, A., and Rios-Insua, S., MOIRA: A decision support System for decision making on aquatic ecosystems Contaminated by radioactive fallout. Annals of Operations Research 95(2000) 341364

8. Gallego, E., Jim'enez, A., Mateos, A., Sazykina, T., \& Rios-Insua, S., Application of multiattribute analysis (MAA) to search for optimum remedial strategies for contaminated lakes with the MOIRA system. Paper presented at the 11th Annual Meeting of the International Radiation Protection Association (Madrid, 23-28 May 2004).

9. Rogers, S. H., Seager,T. P. and Gardner, K.H., Combining expert judgement and stakeholder values with Promethee: A case study in contaminated sediments management, in Comparative Risk Assessment and Environmental Decision Making, eds. I. Linkov \& A. Bakr Ramadan (Kluwer Academic Publishers, Boston, MA 2004), pp. 305-322.

10. I. Linkov, F. K. Satterstrom, G. Kiker, T. P. Seager, T. Bridges, K. H. Gardner, S. H. Rogers, D. A. Belluck, and A. Meyer, Multicriteria Decision Analysis: A Comprehensive Decision Approach for Management of Contaminated Sediments, Risk Analysis, 26(1) (2006) 6178.

11. Stansbury, J., Member, P. E., Bogardi, I., \& Stakhiv, E. Z., Risk-cost optimization under uncertainty for dredged material disposal, J. of Water Resources Planning and Management, 125(6) (1999) 342-351.

12. I. Khadam and J.J. Kaluarachchi, Applicability of riskbased management and the need for risk-based economic decision analysis at hazardous waste contaminated sites, Environment International 29 (2003) 503- 519.

13. I. Khadam and J.J. Kaluarachchi, Multi-criteria decision analysis with probabilistic risk assessment for the management of contaminated ground water, Environmental Impact Assessment Review 23 (2003) 683-721.

14. W.C. Jr. Blackman, Basic Hazardous Waste Management (CRC Press Lewis Publishers, Florida, 1996).

15. Secretariat of the Basel Convention (SBC), 1999 , Technical Guidelines On Hazardous Wastes: PhysicoChemical Treatment Biological Treatment, Basel Convention Series/SBC No: 99/007, Geneva, Switzerland, September 1999.

16. S. Opricovic and G.H.Tzeng, Compromise solution by MCDM methods: a comparative analysis of VIKOR and TOPSIS, European J. of Operational Research 156(2) (2004) 445-455.

17. Wang T.C., Liang J.L. and Ho C.Y., Multi-Criteria Decision Analysis by Using Fuzzy VIKOR, in Proceedings Book of International Conference on Service Systems and Service Management (2006) pp.901 $-906$.

18. Kaya, T. and Kahraman C., 2010, Multicriteria renewable energy planning using an integrated fuzzy VIKOR \& AHP methodology: The case of Istanbul, Energy, 35, 2517-2527.

19. Kaya, T. and Kahraman C., 2011, Fuzzy multiple criteria forestry decision making based on an integrated VIKOR and AHP approach, Expert Systems with Applications (article in publication).

20. D. Yong, Plant location selection based on fuzzy TOPSIS, International J. of Advanced Manufacturing Technologies, 28 (2006) 839-844.

21. TUIK, Statistics of Manufacturing Industry Water, Waste Water and Waste for 2008, TUİK Haber Bülteni 32 (2010). 